\title{
Investigation of Interaction of Vaccinia Virus Complement Control Protein and Curcumin with Complement Components C3 and C3b Using Quartz Crystal Microbalance with Dissipation Monitoring Technology
}

\author{
Amod P. Kulkarni ${ }^{\text {a }}$, Philippa J. Randall ${ }^{\mathrm{a}}$, Krishna Murthy ${ }^{\mathrm{b}}$, Lauriston A. Kellaway ${ }^{\mathrm{a}}$ and Girish J. \\ Kotwal*,c \\ ${ }^{a}$ Division of Neuroscience, Department of Human Biology, University of Cape Town, Cape Town South Africa; \\ ${ }^{b}$ University of Alabama, Birmingham, AL, USA, and ${ }^{c}$ InFlaMed Inc. and Kotwal Bioconsulting LLC, Louisville, KY, USA
}

\begin{abstract}
C3 and C3b, the components central to the complement activation, also play a damaging role in several inflammatory disorders. Vaccinia virus complement control protein (VCP) and curcumin (Cur) are natural compounds with different biological origins reported to regulate complement activation. However, both VCP and Cur have not been investigated for their interaction with the third component (C3) prior to it being converted to its activated form (C3b). These two compounds have also not been compared to each other with respect to their interactions with C3 and C3b. Quartz crystal microbalance with dissipation monitoring (QCM-D) is a novel technology used to study the interaction of biomolecules. This technology was applied to characterize the interactions of VCP, Cur and appropriate controls with the key complement components. Cur as well as VCP showed binding to both $\mathrm{C} 3$ and to $\mathrm{C} 3 \mathrm{~b}$, Cur however bound to $\mathrm{C} 3 \mathrm{~b}$ to a lesser extent.
\end{abstract}

\section{INTRODUCTION}

Complement regulatory molecules might prove beneficial in the prevention of damage to the central nervous system (CNS) from up-regulated complement components in chronic as well as acute neurodegenerative disorders. With the objective of investigating small molecules with an ability to regulate the complement system, VCP was compared to phenolic hydroxy compounds of herbal origin, rosmarinic acid (RA), quercetin (Qur), and curcumin (Cur) by using in vitro techniques [1]. In the past two decades, VCP has been thoroughly investigated for its effect on components of the complement system. VCP was reported to inhibit both the classical pathway (CP) and the alternative pathway (AP) two decades ago [2-4]. It was found to inhibit these pathways by binding to the third and fourth components of the complement [3, 4]. VCP is known to be structurally similar to $\mathrm{C} 4 \mathrm{~B}$ binding protein (C4Bbp), but functionally to $\mathrm{CR} 1$, a human complement regulatory molecule known to bind C3b. VCP has previously been shown to bind to C $3 \mathrm{~b}$ using surface plasmon resonance (SPR) [5]. Similar to VCP, Cur was found to inhibit both the $\mathrm{CP}$ and $\mathrm{AP}$ of complement activation [5]. It is possible that it may also inhibit these pathways through its ability to interact with C3b. Previously, Cur was shown to inhibit the AP activation. It was proposed to show this activity through its ability to prevent the cleavage of factor B to $\mathrm{Bb}$ [1]. It was hypothesized that it might have done so either through binding to $\mathrm{Mg}^{++}$, or through binding to factor $\mathrm{D}$ which cleaves factor $\mathrm{B}$ to generate $\mathrm{Bb}$ fragments. It was also proposed that it might be able to inhibit the formation of $\mathrm{C} 3$ convertases. It may

*Address correspondence to this author at the InFlaMed Inc. and Kotwal Bioconsulting LLC, Louisville, KY, USA;

E-mail: GJKOTW01@gmail.com inhibit stabilization of $\mathrm{C} 3$ convertase by properdin or it may have more than one site of action on the complement components. The complement components that Cur might bind could be the one central to the activation of $\mathrm{CP}$ and AP. Properdin can bind to $\mathrm{C} 3\left(\mathrm{H}_{2} \mathrm{O}\right)$ and $\mathrm{C} 3 \mathrm{~b}$ for the assembly of the $\mathrm{C} 3$ convertase. Complement factor $\mathrm{B}$ and $\mathrm{Bb}$ bind to $\mathrm{C} 3$ $\left(\mathrm{H}_{2} \mathrm{O}\right)$ for the formation of $\mathrm{C} 3$ convertase [6].

Based on our previous results [1] it can be proposed that Cur may bind to $\mathrm{C} 3\left(\mathrm{H}_{2} \mathrm{O}\right)$ and/or $\mathrm{C} 3$ b. By doing so, it may prevent binding of properdin or $\mathrm{Bb}$ to $\mathrm{C} 3$ and $\mathrm{C} 3 \mathrm{~b}$, and thereby inhibit the formation of the AP convertase. $\mathrm{C} 3$ in the form of $\mathrm{C} 3\left(\mathrm{H}_{2} \mathrm{O}\right)$ also acts as a central component of complement activation, which circulates in the body in its inactive form. Upon activation, it is converted into its active fragments such as $\mathrm{C} 3 \mathrm{~b}, \mathrm{C} 3 \mathrm{a}, \mathrm{C} 3 \mathrm{c}$ and $\mathrm{C} 3 \mathrm{~d}$ as discussed in several reviews $[7,8]$. $\mathrm{C} 3 \mathrm{~b}$ and $\mathrm{C} 3 \mathrm{a}$ are reported to play a damaging role in inflammatory disorders. HIV and its proteins are known to increase the expression of $\mathrm{C} 3$ in the neurons and astrocytes [9]. Recently, it was also proposed that HIV uses complement opsonin iC3b, a C3b or C3 fragment, and this opsonized HIV infects T cells [10]. Highly active anti-retroviral therapy (HAART) which is commonly used to treat HIV infections is associated with peripheral neuropathy and elevation of complement components $\mathrm{C} 3$ and $\mathrm{C} 4[8,11]$. $\mathrm{C} 3$ is also implicated in several neuroinflammatory disorders. $\mathrm{C} 3$ and $\mathrm{C} 4$ are expressed in $\mathrm{Clq}$ sufficient and deficient mice [12]. The levels of C3 and C4 are also elevated in Alzheimer's disease with mild to severe clinical symptoms with a low level of expression of complement regulatory molecules [13]. Therefore, there is little doubt that the activated complement components need to be regulated and compounds inhibiting $\mathrm{C} 3$ and $\mathrm{C} 3 \mathrm{~b}$ need to be discovered to prevent the detrimental effects of these complement components. VCP is known to 
inhibit both $\mathrm{C} 3 \mathrm{~b}$ and $\mathrm{C} 4 \mathrm{~b}$. However, VCP's ability to bind to C3 has not been reported. Similarly, Cur's ability to bind C3 and $\mathrm{C} 3 \mathrm{~b}$ has also not been reported. It was therefore considered important to investigate and compare the effect of these components central to the activation of complement by use of specialized techniques.

There are many techniques available for protein adsorption or interaction as cited by Ramsden [14] and Höök [15]. In order to carry out the protein binding study, it was decided to use QCM-D based Q-sense (D-300), a Swedish based technology thoroughly studied and developed for the protein adsorption studies at Chalmers University of Technology, Goetborg, Sweden. The information provided and cited in Hööks thesis and investigations by some other authors are briefly discussed here [15].

\section{COMPARISON OF Q-SENSE WITH OTHER TECHNIQUES}

In order to study protein-protein (P-P) or protein-surface (P-S) interaction / adsorption, many techniques based on various working principles are available. The most extensively used techniques being Optical Wave guided Laser Spectroscopy (OWLS), Ellipsometry (ELM), Surface Plasmon Resonance (SPR), Enzyme Linked Immunosorbent Assay (ELISA), Circular Dichroism (CD), Fourier Transform-Attenuated Total Reflection-Infrared Spectroscopy (FT-ATR-IR), and Quartz Crystal Microbalance (QCM). The first three techniques are based on the principle of optometry; ELISA is a labeling technique; CD is based on the spectroscopic measurement of the differential adsorption of the polarized light; FT-ATR-IR is based on infrared spectroscopy, and QCMD is based on electrical measurements. In Q-sense D-300, which is based on the QCM-D principle, the change in frequency $(\mathrm{dF})$ of a quartz based sensor crystal (i.e.,coated either with a very thin layer of gold or other metals; the gold coated quartz crystals were used for the current investigation) resonating at its resonant frequency $(f)$ upon adsorption of an adsorbing moiety (AM) is correlated with the change in mass of AM. The energy dissipated during this adsorption is also recorded and measured in terms of dissipation factor (D). The changes in dissipation (dD) and $\mathrm{dF}$ are specific for a particular system comprising an $\mathrm{AM}$. The ratio $\mathrm{dD} / \mathrm{dF}$ gives information regarding the viscoelastic property and adsorption kinetics of a system [15].

The comparison of QCM-D and the most extensively used techniques for the P-P and P-S interactions such as SPR, ELM, and OLWS [16] as well as a summary of other available techniques for these studies is thoroughly reviewed by F Hook of the Götenberg University [15]. The information regarding other techniques used for P-P and P-S studies is also readily available in the literature. Each technique has certain advantages and disadvantages and selection of a technique depends upon the information required. Recently QCM-D (Q-sense D300) and SPR (BIACORE) were explored to study the interactions between a peptide antigen (IA-2) and a polyclonal antibody raised against this peptide [17]. The combined data from both these techniques was shown to be effective in reducing the nonspecific binding of the antibodies in sera and detect the antigen at about $0.2 \mathrm{nM}$. Both these non-labeling techniques were found to be comparable to other labeling techniques and offered an advantage of real time monitoring [17]. SPR and QCM-D were also compared in the study of whole blood and plasma coagulation [18]. Both the techniques concluded that blood coagulation is a bulk process and not a surface phenomenon. These techniques were also found to sense the changes in the coagulation process after the addition of activators and inhibitors of blood coagulation. QCM-D has also been compared with the OWLS and ELM for a P-S interaction study [16]. All these techniques were found to be suitable for the kinetics of protein adsorption. The OWLS and ELM directly gave the information regarding mass (dry) of the adsorbed protein, whereas QCM-D gave information regarding the mass of the protein as well as water hydrodynamically coupled to the protein adlayer or bound to the protein. QCM-D also gave additional information regarding the viscoelastic property through the energy of dissipation (D) of the adsorbed layer of protein. This information can be used to obtain detailed information regarding the conformational changes associated with the protein adsorption. QCM-D is based on the principle of QCM with an advantage over QCM and the optical techniques as it gives additional information regarding the rigidity of the binding and possible conformational changes associated with the binding. When QCM was compared with a licensed HIVELISA, a labeling technique, its sensitivity was found be comparable to that of ELISA system [19]. The real time monitoring and short duration for detection $(10 \mathrm{~min} v s$ minimum of $2 \mathrm{~h}$ for ELISA) are the advantages of QCM over ELISA. QCM-D was combined with ELISA to study interaction of fibrinogen with an antifibrinogen monoclonal antibody [20]. The absorbance ratios for $\mathrm{pH}$ dependent denaturation of fibrinogen obtained using ELISA were comparable to the $\mathrm{pH}$ dependent changes in mass of the adsorbed protein or changes in thickness of fibrinogen layer under various $\mathrm{pH}$ conditions measured by QCM-D. This combination was also found to reveal information regarding the changes in conformation of fibrinogen adlayers upon interaction with the anti-fibrinogen monoclonal antibody.

From this discussion, it can be concluded that QCM-D is comparable to the other extensively used techniques to study the P-P and/or P-S interactions. It however offers advantages of real-time monitoring, rapidity, sensitivity, simultaneous detection of viscoelastic properties and mass of the protein layer, and gives additional information regarding the structural and/or conformational changes associated with the protein adsorption.

Under in-vivo conditions, the biological systems such as protein molecules or small sized molecules would interact with each other in their hydrated state. Therefore for appropriate simulation of the in-vivo interactions of the biomolecules such as VCP, tVCP, and Cur with that of the complement system, the information regarding the in-vitro interaction studies of these compounds with the complement components under hydrated conditions would give additional information. For the aforementioned reasons, and the advantages of QCM-D over the other techniques mentioned previously, QCM-D was thought to be the most appropriate method for the current investigation which involves comparison of the P-P, P-S interactions as well as interactions of proteins and small sized molecules. 


\section{PREVIOUS STUDIES WHERE QCM-D WAS USED FOR STUDIES RELATED TO THE COMPLEMENT SYSTEM}

QCM-D has previously been employed to study the interaction of the complement system with biomaterials. J. Andersson from the University of Uppsala, Sweden studied the interaction of complement components with that of biomaterial surfaces [21]. Using QCM-D, it was shown that the polystyrene surface activates the AP of complement activation. C3 deposited on the polystyrene surface can form C3 convertase and activates the AP of complement activation [21]. QCM-D was also compared to ELISA technique to show that biomaterial surfaces activate the complement system and this activation can be inhibited by complement regulatory molecules such as factor $\mathrm{H}$ [22]. Thus Q-sense based on QCM-D may be employed to investigate the complement regulatory molecules of therapeutic importance. In order to confirm binding characteristics, more than one surface should be used to ensure proper comparison.

In the current study the gold and polystyrene sensor (PS) crystals were used to study the interaction with the complement system in hydrophilic and relatively hydrophobic environments, respectively. PS crystals are prepared by applying thin coatings of polystyrene onto the gold coated quartz crystals. PS surface is known to activate the complement system via $\mathrm{C} 3$ offering a special advantage in the study. Cur is known to interact with bovine serum albumin (BSA) [23, 24] and therefore BSA was used as a positive control for the interaction of Cur with $\mathrm{C} 3$ and $\mathrm{C} 3 \mathrm{~b}$.

\section{Objectives}

The objectives of the investigation were to compare the interactions of Cur, VCP, and tVCP with $\mathrm{C} 3$ and $\mathrm{C} 3 \mathrm{~b}$ on the gold and PS surfaces. The specific aims were to compare; (a) the nature of binding of VCP, tVCP, and Cur to $\mathrm{C} 3$ as well as C3b using gold and PS surfaces. (b) the adsorption kinetics of interaction of VCP, tVCP, and bovine serum albumin (positive control for Cur) with the gold and PS. (c) the interaction of $\mathrm{C} 3$ and $\mathrm{C} 3 \mathrm{~b}$ with the aforementioned surfaces as well as with VCP and tVCP adsorbed onto these surfaces and (d) investigation of the modulation of binding of Cur to C3 and C3b bound to the gold and PS surfaces by VCP and tVCP.
Basic principles of QCM, terminologies used, and description of Q-sense (Q-sense manual and discussed and cited by Höök [15]).

QCM is used to measure the interaction between protein or adsorbing molecules and that of the surface as well as with each other, employing a piezoelectric sensor crystal. For QCM studies, this piezoelectric sensor crystal is coated with a very thin layer of gold on both the sides which serve as electrodes which are used to apply an AC voltage. This results in oscillation of the sensor crystal at its resonant frequency $f$. This inherent $f$ of the quartz crystal changes upon adsorption of a thin layer of an AM. In QCM, this change in frequency $(\mathrm{dF})$ is correlated with the change in mass $(\Delta \mathrm{M}$ or $\mathrm{dM})$. The amount of a substance deposited on the crystal surface is determined from this $\mathrm{dF}$ using Sauerbrey's equation as cited in Höök's thesis [15]. The Sauerbrey's equation is based on a few assumptions that the AM should be rigidly and evenly deposited on the crystal. The added mass is smaller than the weight of the crystal. The study of interaction of VCP, tVCP, and Cur with that of C3 and $\mathrm{C} 3 \mathrm{~b}$ was performed under conditions in which these assumptions were valid.

\section{Q-sense: Practical Considerations $[15$ and $Q$ sense manual]}

The equipment used for the current investigation Q-sense (model D-300) makes use of QCM-D technology as discussed above. It consists of four basic components viz. the electronic unit (A), measurement chamber (B), sample holder $(\mathbf{C})$, and the UV chamber for activating the sensor crystal surface (D); (Fig. 1).

In most of the Q-sense based experiments, temperature needs to be controlled appropriately by use of the controller knob of the electronic unit. The experiments are carried out at room temperature $\left(+25{ }^{\circ} \mathrm{C}\right)$ as extremes of temperature may induce aberrant changes in frequency. The temperature inside the chamber for all the experiments was maintained at $24.7{ }^{\circ} \mathrm{C}$. Inside this chamber (Fig. 2), the AT-cut crystals (gold or polystyrene coated; Fig. 3) operated in thickness shear mode at $5 \mathrm{MHz}$ were mounted as per the instructions in the manual.

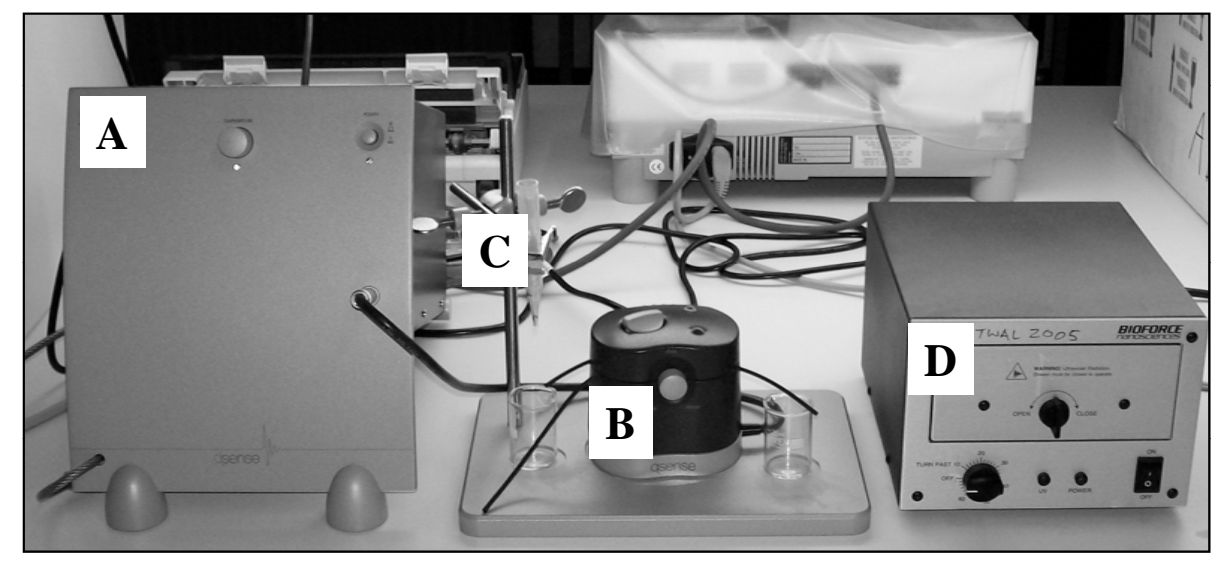

Fig. (1). The Q-sense (D-300) apparatus and its components.

The components of Q-sense (D-300) equipment at UCT showing the electronic unit (A), measurement chamber (B) sample holder (C), and the UV chamber for activating the crystal surface (D) 


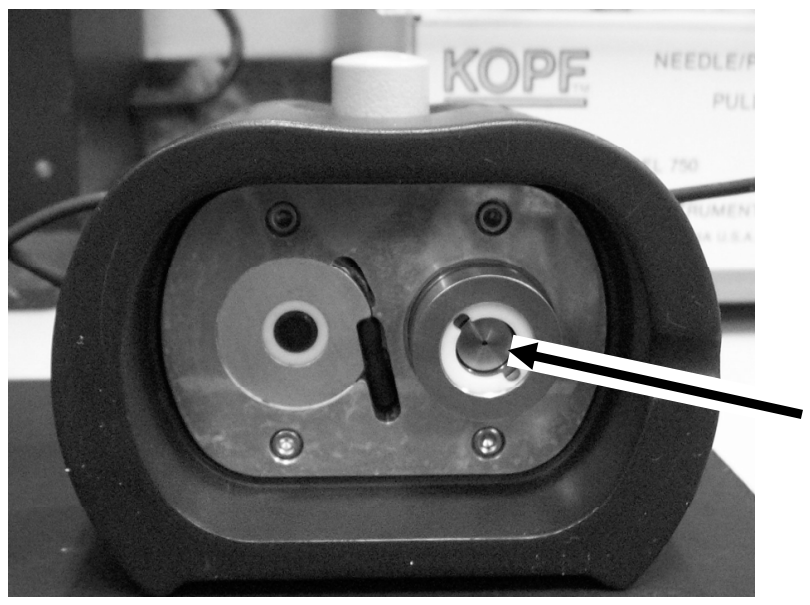

Fig. (2). The Q-sense chamber where the sensor crystal is mounted (shown by an arrow).

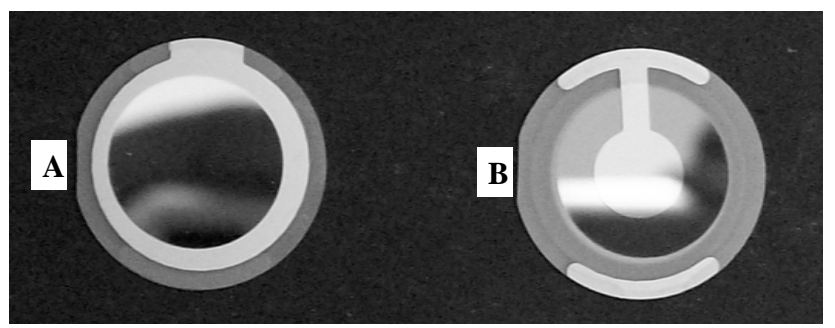

Fig. (3). The gold or PS sensor crystal used in the Q-sense study $(\mathrm{A}=$ Smooth surface exposed to chamber when mounted at the position shown by an arrow in Fig. (2); B = The surface connected to the electronic unit (A) in Fig. (1).

The smooth surface of the crystal is used for the measurements, and the opposite side of the crystal is connected to A/C supply of the electrical unit and operated in a shear thickness mode. The measurement chamber also consists of a sample holder, the position of which can be adjusted to optimize the flow rate. The solution of the AM is kept in this sample holder and it can either be added to the "temperature loop" or to the "sensor crystal" using a controller knob on the measurement chamber. About $2 \mathrm{ml}$ of solution is passed onto the sensor crystal for an accurate measurement.

The chamber is connected to a $\mathrm{PC}$ and the change in $f$ and $\mathrm{D}$ is monitored online at different overtones using q-soft software. The q-tools software provided with the equipment is used for the analysis of the data captured using q-soft. Using q-tools, it is first confirmed whether the adsorption of AM follows the Sauerbrey law using fit analysis. If the adsorption doesn't follow the Sauerbrey equation, a method called Z-match and/or viscoelastic modeling is recommended. As discussed earlier, the change in frequency upon adsorption is correlated with the mass adsorbed on the sensor crystal to study the adsorption of AMs used in the study.

\section{Dissipation Factor in QCM [15]}

In advanced QCM, the important factor that needs to be taken into consideration is the "Q factor". This $\mathrm{Q}$ factor is determined experimentally as the ratio of the resonance frequency $(f r)$ to the bandwidth (denoted by "w" being the difference between the maximum and minimum cut-off frequencies). This ratio when inverted $(\mathrm{w} / f)$ gives information regarding the energy lost during one complete oscillation and is defined as the dissipation (D) factor. The D factor is calculated by measuring the decay of the oscillation amplitude of the electrode after the AC voltage is disconnected. The faster the decay, the higher is the dissipation.

The $\mathrm{D}$ factor gives information regarding the energy dissipated during one oscillation after adsorption of the AM on the crystal. This factor is very important when considering dissipative losses introduced by the mass load in an oscillating system. When the change in $\mathrm{D}$ factor is divided by the change in frequency $(\mathrm{dD} / \mathrm{dF})$, it gives information regarding rigidity of binding. The low values of this ratio indicate stronger binding. The D-shifts or change in $\mathrm{D}$ values are attributed to dissipation at three interfaces [2527].

\section{Materials}

$2 \mathrm{mg} / \mathrm{ml}$ of Cur solution was prepared freshly prior to adsorption during each experiment as described elsewhere [1]. To prepare VCP solution, approximately $50 \mu$ l of 1.2 $\mathrm{mg} / \mathrm{ml}$ of endotoxin-free extra pure $\mathrm{rVCP}$ was diluted to $2 \mathrm{ml}$ using ice cold PBS solution at the time of experiment. The tVCP used in the study was purified by desalting and by washing with PBS and concentrated by passing the solution several times through a $5 \mathrm{kDa}$ cut-off filter. The final concentration of tVCP was 1.8767 times higher than that of VCP supplied and its molecular weight $(18.8 \mathrm{kDa})$ is 1.5319 times less than that of rVCP $(28.8 \mathrm{kDa})$. In order to prepare tVCP of the same concentration, $40.82 \mu \mathrm{l}$ to $76.06 \mu \mathrm{l}$ of tVCP was dissolved in $2 \mathrm{ml}$ of PBS solution prior to experimentation. $\mathrm{C} 3$ and $\mathrm{C} 3 \mathrm{~b}$ solution of the same molar strength were used. To prepare C3 and C3b solution, $15 \mu \mathrm{l}$ of $2 \mathrm{mg} / \mathrm{ml} \mathrm{C} 3$ was diluted in $2 \mathrm{ml}$ and $20 \mu \mathrm{l}$ of approximately $1.6 \mathrm{mg} / \mathrm{ml}$ of $\mathrm{C} 3 \mathrm{~b}$ was diluted in $2 \mathrm{ml}$ in PBS prior to the experiment. BSA used in the experiment was prepared by diluting $42.2 \mu \mathrm{l}$ of $2 \mathrm{mg} / \mathrm{ml}$ of BSA in $2 \mathrm{ml}$ of PBS. PBS (Gibco, Invitrogen or prepared in the laboratory; $0.154 \mathrm{M}$; $\mathrm{pH}$ 7.2). The solutions were passed through a $0.22 \mu \mathrm{M}$ filter and degassed prior to use. Two sensor crystals [gold (g) and polystyrene (PS)] were used in the experiments. Hydrogen peroxide (30\% approx), Liquid ammonia, concentrated $\mathrm{HCl}$ used for washing the sensor crystals were either of analytical or molecular grade. The water used in the experiment and/or to wash the sensor crystal surface was of deionized double distilled Millipore grade $\left(\mathrm{dd}_{2} \mathrm{O}\right)$, and it was degassed prior to use.

\section{Methods}

\section{Preparation of the Surface and the Chamber Prior to Use}

Just before starting the experiment, and after completion of the experiment, the sensor crystal was washed in appropriate cleansing solution as mentioned in the instruction manual. For washing PS crystal, piranha solution ( $\mathrm{HCl}: \mathrm{H}_{2} \mathrm{O}_{2}: \mathrm{H}_{2} \mathrm{O}$ ) was used. A cocktail of ammonia: water: hydrogen peroxide was used for washing the gold crystal. The chamber was washed with $1 \%$ Hellmanex-II solution. 
After each washing step, the sensor crystals as well as the chamber were dried using nitrogen gas. The sensor crystal was exposed to UV light for 5-10 minutes to destroy impurities on the sensor surface. It was ensured that resonant frequencies of the crystals matched the values as per the instruction manual. For all the experiments, only the crystals showing comparable and similar pattern of $\mathrm{F}$ and $\mathrm{D}$ values were used. The final volume of each AM used was $2 \mathrm{ml}$. PBS was used to obtain a baseline before starting each experiment as well as prior to each adsorption.

\section{Experiments}

Prior to the adsorption of AM, a baseline for $f$ of the crystal was obtained by adding PBS $(\mathrm{pH}=7.2 ; 154 \mathrm{mM})$ to the surface. PBS was added until there was no further drop in the frequency. The surfaces, AMs used, and the sequence of AMs are as described in the Table 1. As shown in the table, VCP and tVCP were adsorbed on either PS or gold surface and their interaction with $\mathrm{C} 3$ and $\mathrm{C} 3 \mathrm{~b}$ was measured. In the case of Cur, first $\mathrm{C} 3$ and $\mathrm{C} 3 \mathrm{~b}$ were deposited on the surface of the sensor crystal and Cur was adsorbed. After adsorption of the first compound on the sensor crystal for a particular period of time (approximately 30-50 min), $2 \mathrm{ml}$ of the second AM was added to the sensor surface to adsorb on the first AM. The adsorption was continued for approximately the same period. The third step was either final washing and I or continuation of the experiment by adsorbing the third $\mathrm{AM}$ on the second AM. Generally the $3^{\text {rd }} \mathrm{AM}$ was used after the adsorption of $\mathrm{C} 3$ or $\mathrm{C} 3 \mathrm{~b}$ onto $\mathrm{VVCP}$ or $\mathrm{VCP}$, which in turn was bound to the gold or PS surface. In these cases, Cur was adsorbed onto $\mathrm{C} 3$ or $\mathrm{C} 3 \mathrm{~b}$. This was done to check whether Cur can bind to $\mathrm{C} 3$ or $\mathrm{C} 3 \mathrm{~b}$ adsorbed onto $\mathrm{VCP}$ or tVCP to investigate whether Cur and these drugs share common binding sites. The $\mathrm{dF}$ and $\mathrm{dD}$ values were measured online and plotted using Q-soft software. The $\mathrm{dD} / \mathrm{dF}$ ratios were calculated to get information regarding rigidity of binding molecules. $\mathrm{dD}$ values ( $\mathrm{Y}$ axis) at different time intervals were plotted against $d f$ values at the same interval to get information regarding the kinetics of binding. Avogadro's formula (shown in the sections $\mathrm{d}$ and $\mathrm{e}$ of the terminology section) was used to calculate the number of molecules of one compound. However, in the current experiment, as the water binding capacity of VCP, tVCP, and Cur was not known, the number of molecules bound to each other and with the surface is not true reflection, but an approximate value. As discussed later in the appropriate section, 30\% mass accounts for the water bound to protein molecules, and therefore it was deducted from the final mass of AMs interacting with the surfaces or other AMs. As this was not the main objective, and also that viscoelastic modeling of more than 30 experiments was beyond the scope of the objectives in this study, the results for approximate number of binding molecules are not included.

\section{Terminology Used in the Results and Discussion}

As discussed in the above section, there were two to three AMs used for the study. AMI = AM bound to the surface of the sensor crystal (gold or PS). Therefore, AMI is indicated by putting the first letter of the surface $(\mathrm{g}=$ gold; $\mathrm{ps}=$ polystyrene) in lower case, next to AMI. The abbreviations used in the results and discussion are as mentioned below:

Table 1. The Outline of Q-Sense Experiments

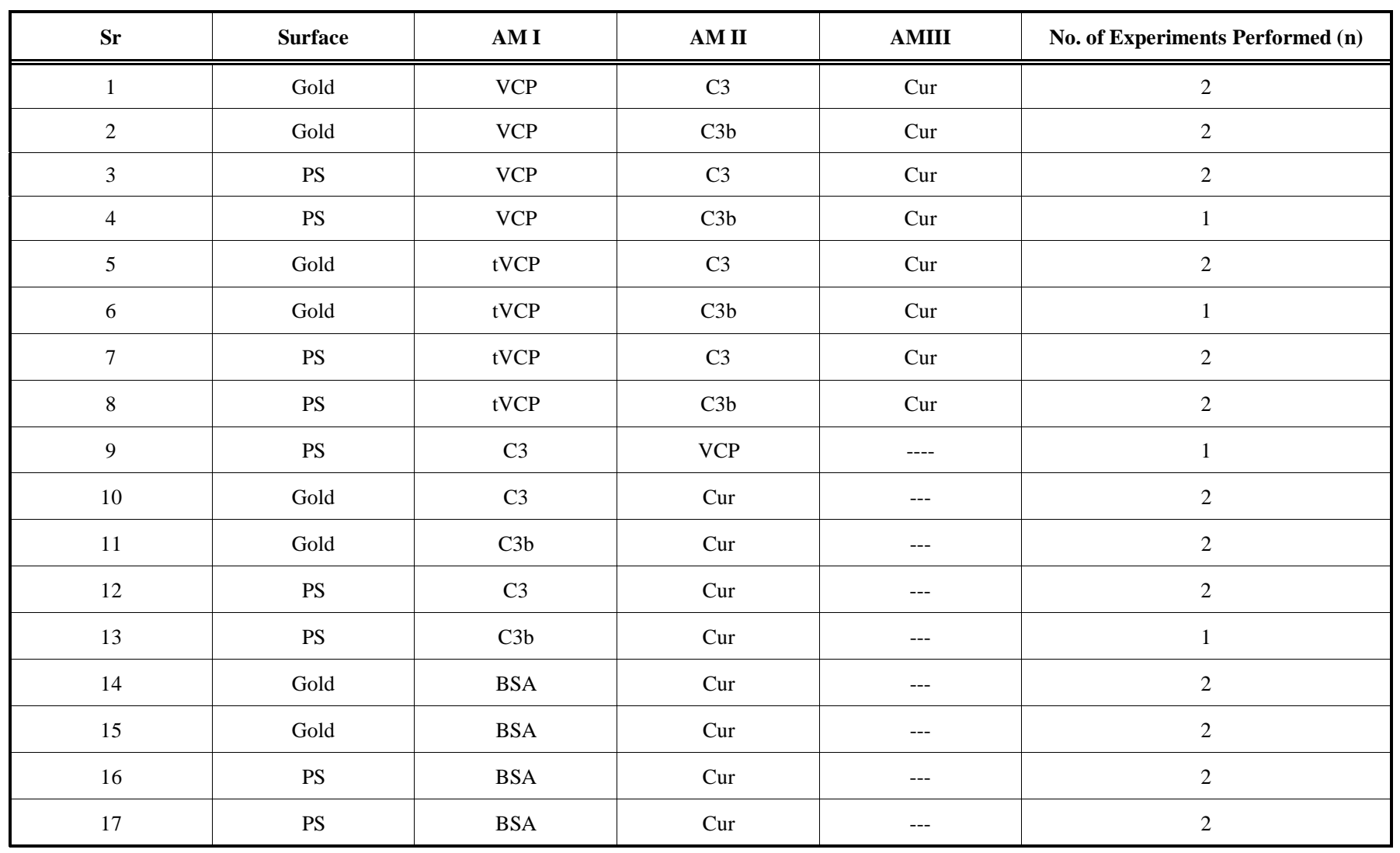

The surface coating of the crystal, and the sequence of AMs (AMI, AMII, and AMIII) and the number of experiments performed per serial number (Sr). 
1. Where AM is bound to the surface of the sensor crystal (AMI), where it is either gold or PS, the abbreviations are VCPg, VCPps, tVCPg, tVCPps, C3g, C3ps, C3bg, C3bps, BSAg, and BSAps.

2. Where AMII is bound to AMI bound to the surface of the sensor crystal (g or ps) as shown in the table 3.1, the abbreviations are $\mathrm{C} 3-\mathrm{VCPg}, \mathrm{C} 3-\mathrm{VCPps}$, Cur-C3g, Cur-C3bps, etc.

3. Where AMIII is bound to the AMII adsorbed onto AMI as described above and shown in the table 3.1, the abbreviations are Cur-C3VCPg, Cur-C3VCPps, Cur-C3tVCPg, etc.

Most of the experiments were carried out for $30 \mathrm{~min}$, therefore, $\mathrm{dF}_{30}$ and $\mathrm{dD}_{30}$ refers to $\mathrm{dF}$ and $\mathrm{dD}$ values after 30 min, respectively. $\mathrm{dF}_{30}$ and $\mathrm{dD}_{30}$ values for $\mathrm{AMs}$ were calculated as follows:

1. $\mathrm{dF}_{30}=\mathrm{dF}$ at $30 \mathrm{~min}-\mathrm{dF}_{\text {initial }}$, where $\mathrm{dF}_{\text {initial }}$ refers to the baseline or initial $\mathrm{f}$ or $\mathrm{D}$ values prior to the adsorption of AMs

2. In some of the experiments, the adsorption was continued for more than $30 \mathrm{~min}$ (and rarely less than $30 \mathrm{~min})$. In those cases, in addition to $\mathrm{dF}_{30}$ or $\mathrm{dD}_{30}$ values, $\mathrm{dF}_{\text {fin }}$ or $\mathrm{dD}_{\text {fin }}$ values were also calculated. These values were recorded after washing the surface with PBS after the adsorption was over and were calculated as: $\mathrm{dF}_{\text {fin }}\left(\right.$ or $\left.\mathrm{dD}_{\text {fin }}\right)=$ Final $\mathrm{dF}$ (or $\mathrm{dD}$ ) values after washing with $\mathrm{PBS}-\mathrm{dF}_{\text {initial }}$ (or $\mathrm{dD}_{\text {initial }}$ ).

3. Using these $\mathrm{dD}$ and $\mathrm{dF}$ values, $\mathrm{dD} / \mathrm{dF}$ ratios were calculated to get the information regarding the rigidity (affinity) or viscoelasticity of binding.

4. No. of molecules of AM adsorbed onto the crystal surface or onto the other $\mathrm{AM}=6.022 \times 10^{23} \mathrm{X}$ mass adsorbed $\left(\mathrm{ng} / \mathrm{cm}^{2}\right) /$ molecular weight of the AM.

5. Molecular weights of $\mathrm{C} 3, \mathrm{C} 3 \mathrm{~b}, \mathrm{Cur}, \mathrm{BSA}$, and tVCP in nanograms (ng) were $1900 \times 10^{11}, 1800 \times 10^{11}$, $3.6839 \times 10^{11}, 680 \times 10^{11}, 188 \times 10^{11}$, and $288 \times$ $10^{11}$, respectively. These values were taken either from Calbiochem catalogue (C3 and C3b), SigmaAldrich (Cur) or from the literature (VCP and tVCP).

\section{Guide to the Interpretation of the Figs. (4 to 7)}

These figures comprise both the primary and secondary axes. The primary $\mathrm{X}$ and $\mathrm{Y}$ axes are shown by solid black lines, whereas the secondary $\mathrm{X}$ and $\mathrm{Y}$ axes are shown by ultrafine hatched black lines. The primary $X$ axis represents AMs (Please refer to the terminology section above for the meaning of the abbreviations used for AMs). The primary $\mathrm{Y}$ axis shows $\mathrm{dD} / \mathrm{dF}$ ratios for AMs shown on the primary $X$ axis. Two different sets of $\mathrm{dD} / \mathrm{dF}$ values for the AMs are shown by solid black bars and hatched bars. The solid black coloured bars indicate the average values after $30 \mathrm{~min}$ $\left(\mathrm{dD}_{30 \mathrm{avg}} / \mathrm{dF}_{30 \mathrm{avg}}\right)$ and the hatched bars indicate the average final values after washing the sensor surfaces once the experiments have been completed $\left(\mathrm{dD}_{\text {Finavg }} / \mathrm{dF}_{\text {finavg }}\right)$. The secondary $\mathrm{Y}$ axis represents $\mathrm{dF}$ values for the AMs shown on the primary $\mathrm{X}$ axis. The gradient black bars plotted on the secondary $X$ and $Y$ axes represent $d_{F}$ values. The $d_{30}$ values are also displayed on the secondary axis for a quick reference. The gradient black dots connected by a hatched black line are used to show the dFfin values of AMs on the primary $\mathrm{X}$ axis. It should be noted that for some of the AMs, $\mathrm{dF}_{30}$ or dFfin values plotted on the secondary $\mathrm{X}$ axis of these graphs were high and the bars for these values were overlapping with the $\mathrm{dD} / \mathrm{dF}$ bars plotted on the primary axis, when 'zero' was used as the point of origin. In order to avoid this overlapping, the point of origin of the graphs is a negative value although such negative values do not have any physical reality $\mathrm{VCPhc}$ refers to VCP used at a higher concentration.

\section{Guide to the Interpretation of the Figs. (8 to 10)}

In order to discuss the results of the kinetics of binding of AMs, dD values (Y-axis) at five different time points were plotted against $\mathrm{dF}$ values (X-axis) at the same time points. $\mathrm{dD}$ vs $\mathrm{dF}$ graphs are plotted to avoid time dependency and to understand the shapes of the graph in order to study the phases and kinetics of adsorption. Therefore the zero values used in the current graphs indicate neither time points nor do these values indicate data points. The zero values are however used to get information regarding the slope of the graph during the first phase of adsorption (zero to $1 \mathrm{~min}$ ). The adsorption during this period in some of the cases is rapid whereas it is relatively slower in some other cases. In order to get a comparative account of kinetics of adsorption of different AMs during this first phase of adsorption, it was considered necessary to use 'zero' as the point of origin for these graphs.

\section{RESULTS}

\section{Binding of AMs to C3 on PS}

\section{Results (Fig. 4)}

When VCP (AMII) was adsorbed on C3 bound to PS (AMI), it did not get adsorbed on C3 (VCP-C3ps in Fig. 4). Similar results were obtained when the attempts were made to adsorb on $\mathrm{C} 3$ and $\mathrm{C} 3 \mathrm{~b}$ bound to the gold and PEG-COOH crystal surface (unpublished data). Therefore, in the current investigation, VCP and tVCP were first adsorbed on the gold or PS surface, and C3 and C3b were then adsorbed on them.

As shown in Fig. (4), $\mathrm{dD} / \mathrm{dF}$ ratio for the binding of VCPhc adsorbed on PS to C3 (C3-VCPhcps) is very low (0.0005 after $30 \mathrm{~min}$ and 0.0002 after the final binding and washing with PBS) suggesting a very strong binding of VCP to $\mathrm{C} 3$. As shown in Fig. (4), the order for $\mathrm{dD} / \mathrm{dF}$ ratios for the different AMs is: $\mathrm{C} 3$ vs VCPhcps $\ll<\mathrm{C} 3$ vs VCPps = $\mathrm{C} 3$ vs tVCPps = C3 vs tVCPhcps $<\mathrm{VCP}$ vs $\mathrm{C} 3 \mathrm{ps}$. The $\mathrm{dD} / \mathrm{dF}$ ratio for Cur vs $\mathrm{C} 3 \mathrm{ps}$ was lower than that for Cur vs BSAps, and higher than that for VCP vs C3ps. The ratio was the lowest for C3 vs VCPhcps and it was the highest for Cur vs BSAps. $\mathrm{dF}_{30}$ and $\mathrm{dF}_{\text {fin }}$ were of the following order: $\mathrm{C} 3$ vs VCPps > C3 vs tVCPhcps > C3 vs tVCPps > C3 vs VCPhcps $>$ Cur vs C3ps > Cur vs BSAps > VCP vs C3.

\section{Results (Fig. 5)}

$\mathrm{dD} / \mathrm{dF}$ ratios for the binding of AMs to $\mathrm{C} 3$ on the gold surface (Fig. 5) were of the following order: C3 vs $\mathrm{VCPg}<$ $\mathrm{C} 3$ vs $\mathrm{tVCP}<\mathrm{Cur}$ vs $\mathrm{C} 3 \mathrm{~g}<\mathrm{Cur}$ vs $\mathrm{BSAg}$ and the $\mathrm{dF}_{30}$ and $\mathrm{dF}_{\text {final }}$ values were found to be the highest for C3 - VCPg and the lowest for Cur vs BSAg (order: $\mathrm{C} 3$ vs $\mathrm{VCPg}>\mathrm{C} 3$ vs tVCPg > Cur vs C3g > Cur vs BSAg. 


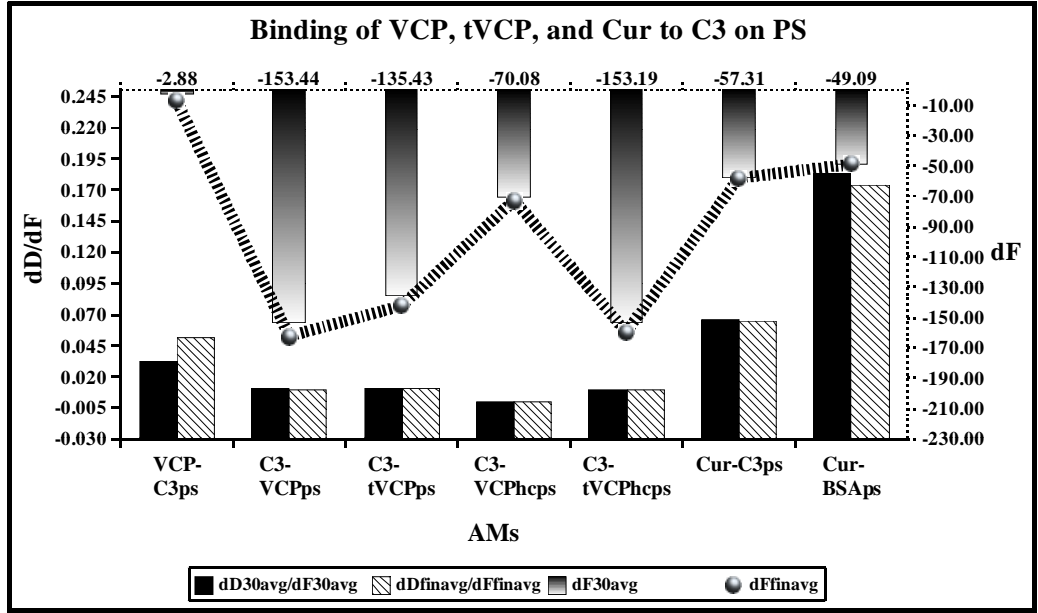

Fig. (4). $\mathrm{dD} / \mathrm{dF}$ ratios (the primary $\mathrm{X}$ and $\mathrm{Y}$ axis) and $\mathrm{dF}$ values (the secondary $\mathrm{Y}$ axis [right] and the secondary $\mathrm{X}$ axis shown [top] by ultrafine dotted lines) for binding of VCP, tVCP, Cur, and C3 on PS. dD/dF ratios at 30 min interval are shown by solid black bars whereas final $\mathrm{dD} / \mathrm{dF}$ ratios are shown by hatched bars. The $\mathrm{dF}_{30}$ values are shown by a gradient black bar whereas the $\mathrm{dF}_{\text {fin }}$ values are shown by a black hatched line with gradient black dots ( $\left.{ }^{\prime \prime \prime} \cdot{ }^{\prime \prime \prime}\right)$. The $\mathrm{dF}$ and $\mathrm{dD}$ values shown indicate the average values obtained from the two experiments unless specified in the Table 1.

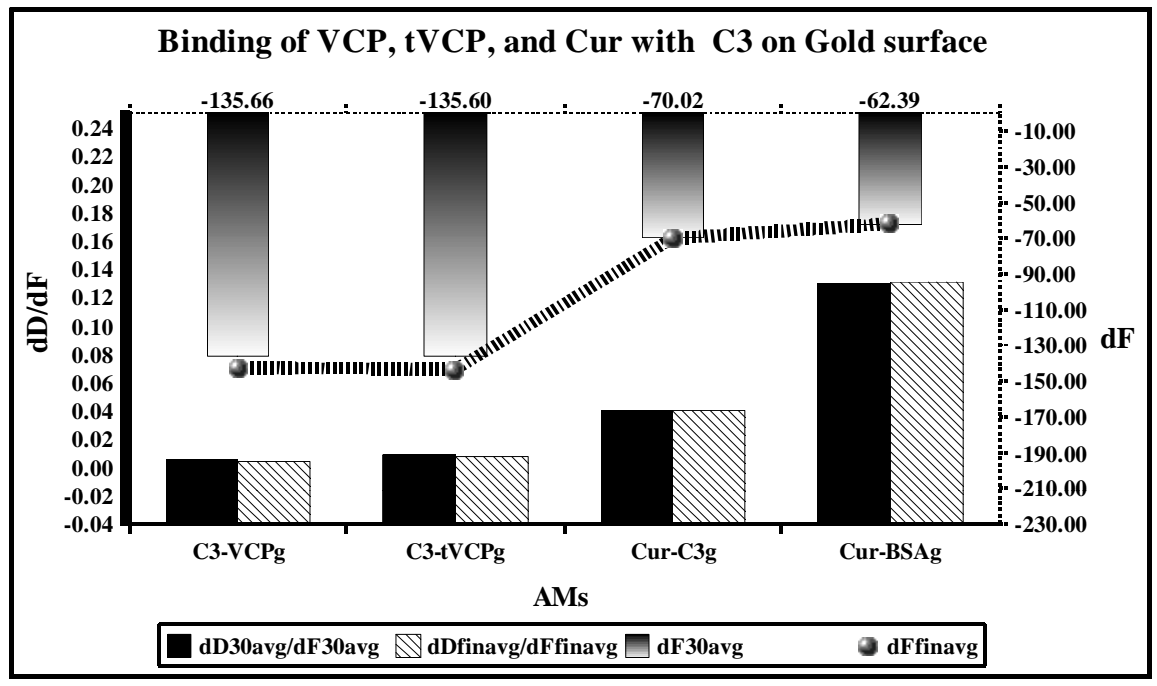

Fig. (5). dD/dF ratios (the primary $\mathrm{X}$ [bottom] and $\mathrm{Y}$ axis [black; left]) and $\mathrm{dF}$ values (the secondary $\mathrm{Y}$ axis [right] and $\mathrm{X}$ axis [Top] are shown by ultrafine dotted lines at the top) for the binding of VCP, tVCP, Cur and C3 on the gold surface are as shown in this figure. dD/dF ratios at 30 min interval are shown by solid black bars whereas final $\mathrm{dD} / \mathrm{dF}$ ratios are shown by hatched bars. The $\mathrm{dF}_{30} \mathrm{values}$ are shown by a gradient black bar whereas the final $\mathrm{dF}$ values are shown by the black line with gradient black dots ("'m'm). The $\mathrm{dD} / \mathrm{dF}$ ratios and $\mathrm{dF}$ values indicate average of the values obtained from two experiments unless specified in the Table $\mathbf{1}$.

\section{Binding of AMs to C3b on PS}

\section{Results (Fig. 6)}

The $\mathrm{dD} / \mathrm{dF}$ values for the binding of AMs to C3b were found to be of the following order: C $3 \mathrm{~b} v s \mathrm{tVCP} \leq \mathrm{C} 3 \mathrm{~b} v s$ VCP < Cur vs C3bps < Cur vs BSAps. For the $\mathrm{dF}$ values, the order was C3b vs VCPps > Cur vs BSAps > Cur vs C3bps.

\section{Binding of AMs to C3b on Gold Surface}

\section{Results (Fig. 7)}

The order of $\mathrm{dD} / \mathrm{dF}$ values (Fig. 7) for the binding to $\mathrm{C} 3 \mathrm{~b}$ on the gold surface is VCP vs C3bg $<\mathrm{tVCP} v s \mathrm{C} 3 \mathrm{~b}<\mathrm{Cur} v s$ C3bg < Cur vs BSAg. As far as the $\mathrm{dF}$ value is concerned, Cur vs BSA > VCP vs C3b > VCP vs Cur > tVCP vs C3b.

\section{Adsorption Kinetics for the Interaction of $\mathrm{VCP}$ and tVCP with $\mathrm{C} 3$ and $\mathrm{C} 3 \mathrm{~b}$}

\section{Results (Figs. 8 and 9)}

As shown in Fig. (8), in almost all the experiments to study the interaction of $\mathrm{C} 3$ with that of VCP and tVCP on the gold and PS surfaces, VCP and tVCP were adsorbed on these surfaces. The $\mathrm{dD} v s \mathrm{dF}$ graphs for most of the AMs were linear during the initial stages of adsorption which constitute phase I of the adsorption. For almost all the AMs, the phase I was followed by the second phase where $\mathrm{dD}$ values changed only slightly with $\mathrm{dF}$. The adsorption of $\mathrm{C} 3$ on VCPhcps however was a single phase phenomenon as shown by a linear graph. For VPheps, throughout the 


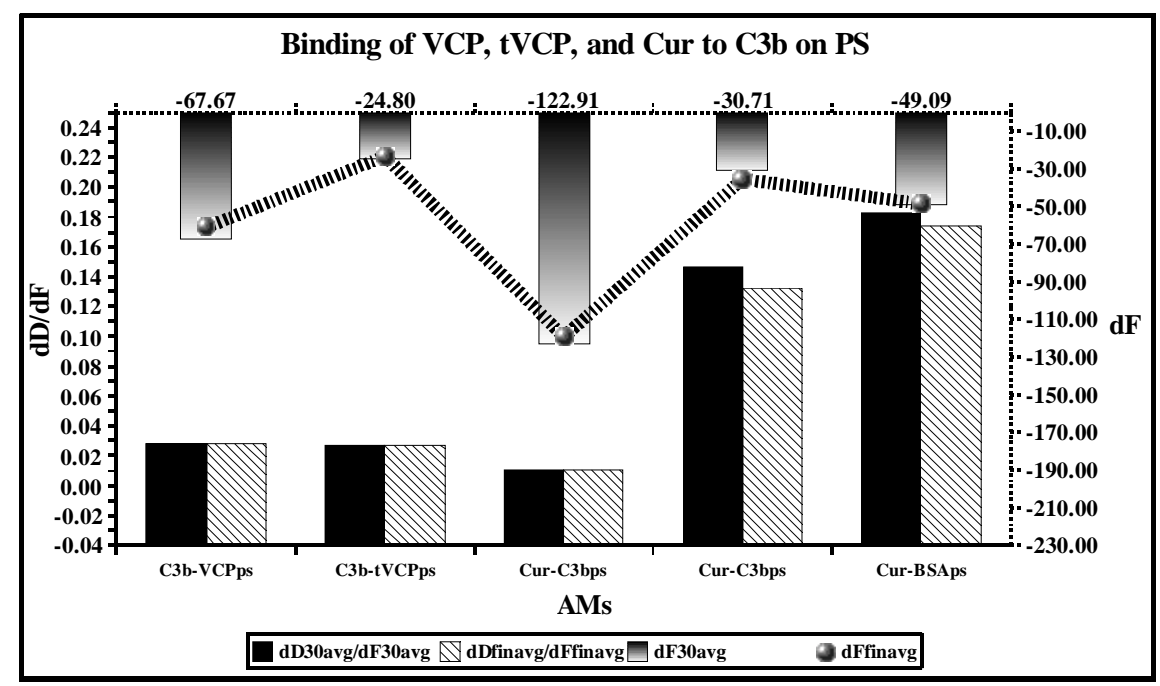

Fig. (6). $\mathrm{dD} / \mathrm{dF}$ ratios (the primary $\mathrm{X}$ and $\mathrm{Y}$ axis) and $\mathrm{dF}$ values (the secondary $\mathrm{Y}$ axis [right] and and secondary $\mathrm{X}$ axis [Top] shown by ultrafine dotted lines) for binding of VCP, tVCP, Cur and C3b on PS are as shown in this figure. dD/dF ratios at 30 min interval are shown by solid black bars whereas final $\mathrm{dD} / \mathrm{dF}$ ratios are shown by hatched bars. The $\mathrm{dF}_{30}$ values are shown by gradient black bars whereas the final $\mathrm{dF}$ values are shown by a black hatched line bearing gradient black dots ( $\left.{ }^{\prime \prime \prime} \mathrm{m} \cdot \mathrm{m}\right)$. The $\mathrm{dD} / \mathrm{dF}$ ratios and $\mathrm{dF}$ values indicate average of the values obtained from the two experiments unless specified in the Table $\mathbf{1}$.

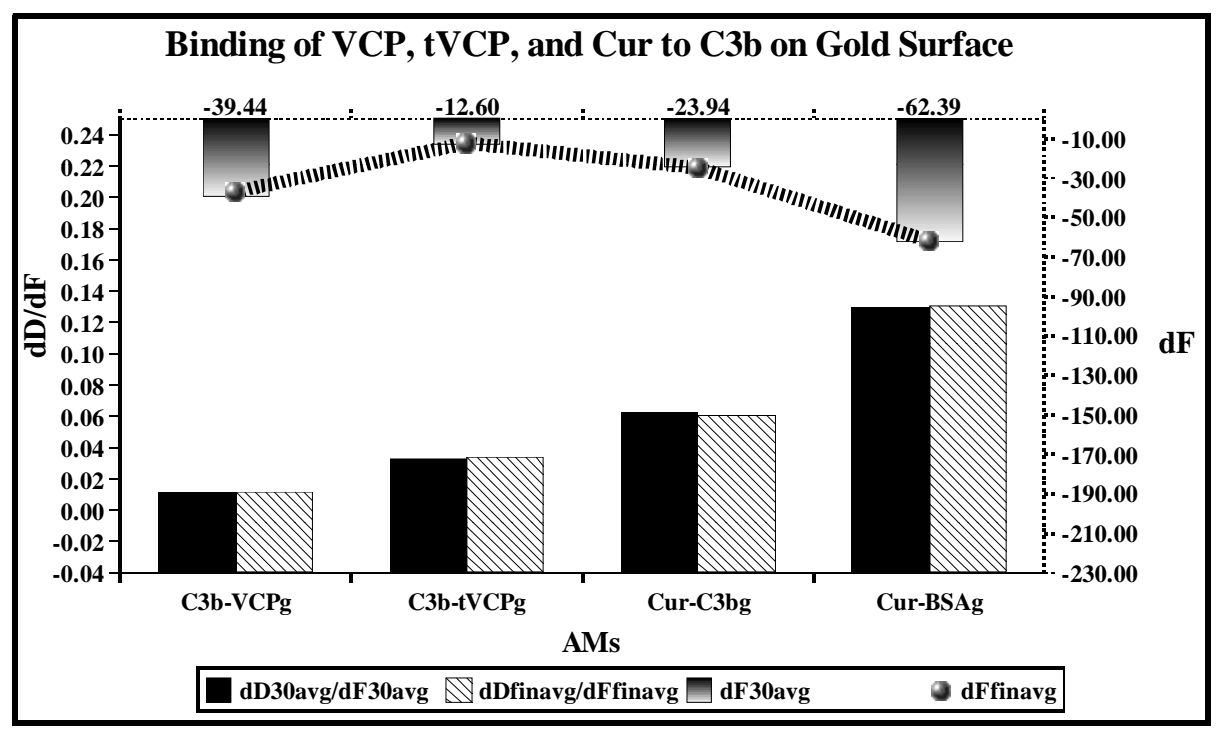

Fig. (7). $\mathrm{dD} / \mathrm{dF}$ ratios (Primary $\mathrm{X}$ [bottom] and $\mathrm{Y}$ axis [black, left]) and dF values (secondary $\mathrm{Y}$ axis [ultrafine dotted; right] and the secondary X [ultrafine dotted; top]) for binding of VCP, tVCP, Cur and C3b on gold surface are as shown in this figure. $\mathrm{dD} / \mathrm{dF}$ ratios at 30 min interval are shown by solid black bars whereas final $\mathrm{dD} / \mathrm{dF}$ ratios are shown by hatched bars. The $\mathrm{dF}_{30}$ values are shown by gradient black bars whereas the final $\mathrm{dF}$ values are shown by a black hatched line with gradient black dots ('"m!'m). $\mathrm{dD} / \mathrm{dF}$ ratios and $\mathrm{dF}$ values indicate an average of the values obtained from two experiments unless specified in the Table $\mathbf{1}$.

adsorption, the $\mathrm{dD}$ values were close to zero and the $\mathrm{dF}$ values dropped up to $-72 \mathrm{~Hz}$ in $30 \mathrm{~min}$.

In most of the experiments carried out for the investigation of the interactions of $\mathrm{VCP}$ and $\mathrm{tVCP}$ with $\mathrm{C} 3 \mathrm{~b}$ (Fig. 9), adsorption was a linear phenomenon as $\mathrm{dD}$ values show a steady rise per unit decline in $\mathrm{dF}$ values. The final $\mathrm{dF}_{30}$ values for the adsorption of $\mathrm{C} 3 \mathrm{~b}$ are between $-25 \mathrm{~Hz}$ to $40 \mathrm{~Hz}$ for all the adsorptions with an exception of $\mathrm{C} 3 \mathrm{~b}$ VCPps (above $-60 \mathrm{~Hz}$ ). Also, for the adsorption of $\mathrm{C} 3 \mathrm{~b}$ on
VCP, there is a steady increase in $\mathrm{dD}$ values with the decrease in $\mathrm{dF}$ values till $-40 \mathrm{~Hz}$, however the rate of change of $\mathrm{dD}$ values per unit change in $f$ dropped to a certain extent resulting in the second phase of adsorption. The decline during this second phase of C3b-VCPps adsorption was not as sharp as the decline during C3-VCPps adsorption. The graphic evidence shows that for most of the $\mathrm{C} 3 \mathrm{~b}$ adsorptions, the $\mathrm{dD}$ values per unit $\mathrm{dF}$ values are higher than that for the adsorption of $\mathrm{C} 3$. 


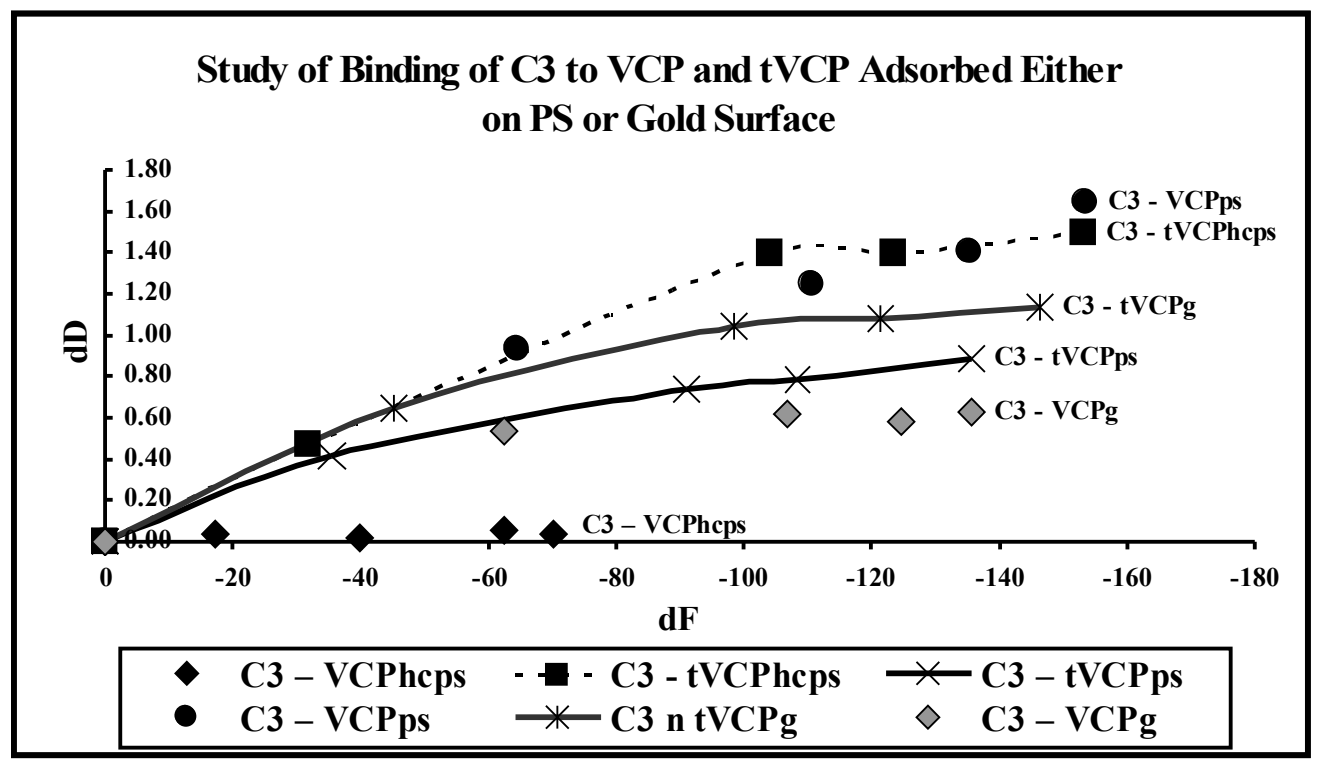

Fig. (8). $\mathrm{dF}$ values for the interaction of VCP and tVCP adsorbed either on the gold or ps surfaces with C3 ( X-axis) were plotted against dD values (Y-axis). The data label for each series indicates AMs (Series: C3-VCPhcps, C3-tVCPhcps, C3-tVCPps, and C3-VCPg indicate adsroption of $\mathrm{C} 3$ on VCPhcps, tVCPhcps,tVCPps, and VCPg, respectively. "hc" prior to ps in the case of VCP denote VCP at high concentration).

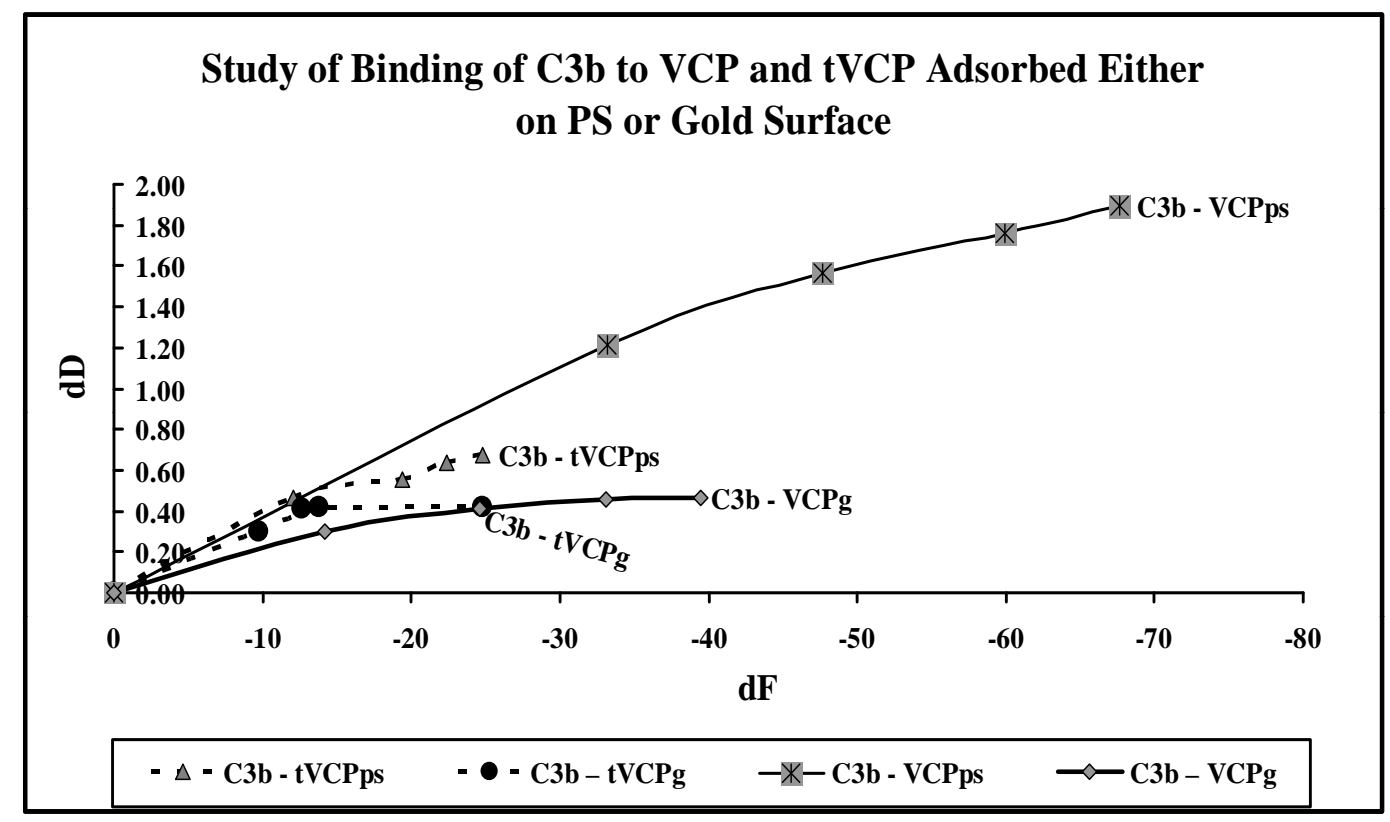

Fig. (9). $d F$ values for the interaction of VCP and tVCP adsorbed either on the gold or ps surfaces with C3b ( X-axis) were plotted against dD values (Y-axis). The data label for each series indicates AMs (Series: C3b-VCPps, C3b-VCP, C3b-tVCPps, and C3b-tVCPg indicate adsorption of C3b on VCPps, VCPg, tVCPps, and tVCPg.

Adsorption Kinetics for the Interaction of Cur with $\mathrm{C3}$ and C3b

Results (Figs. 10A, 10B, and 10C)

As shown in Fig. (10A), the adsorption of Cur on C3, $\mathrm{C} 3 \mathrm{~b}$ and BSA was either a single phase or two phase phenomenon. For Cur-C3g, Cur-C3bg, Cur-C3ps, CurC3bps, Cur-BSAg, Cur-C3tVCPg, and Cur-C3tVCPhcps, the second phase started at $-60 \mathrm{~Hz},-20 \mathrm{~Hz},-50 \mathrm{~Hz},-15 \mathrm{~Hz},-70$ $\mathrm{Hz},-90 \mathrm{~Hz}$, and $-30 \mathrm{~Hz}$, respectively.

Cur-C3VCPhcs, Cur-C3tVCPg (Fig. 10B), and Cur-C3btVCPg (Fig. 10C) also showed similar two phase adsorption, the second phase starting at $-40 \mathrm{~Hz}$ $(\mathrm{dD}=$ Approx 9), $-28 \mathrm{~Hz}(\mathrm{dD}=$ Approx 5.7$)$, and $-40 \mathrm{~Hz}(\mathrm{dD}$ = Approx 6), respectively. For Cur-C3VCPg (Fig. 10B), during the first phase of adsorption, there was a rise in $\mathrm{dD}$ 


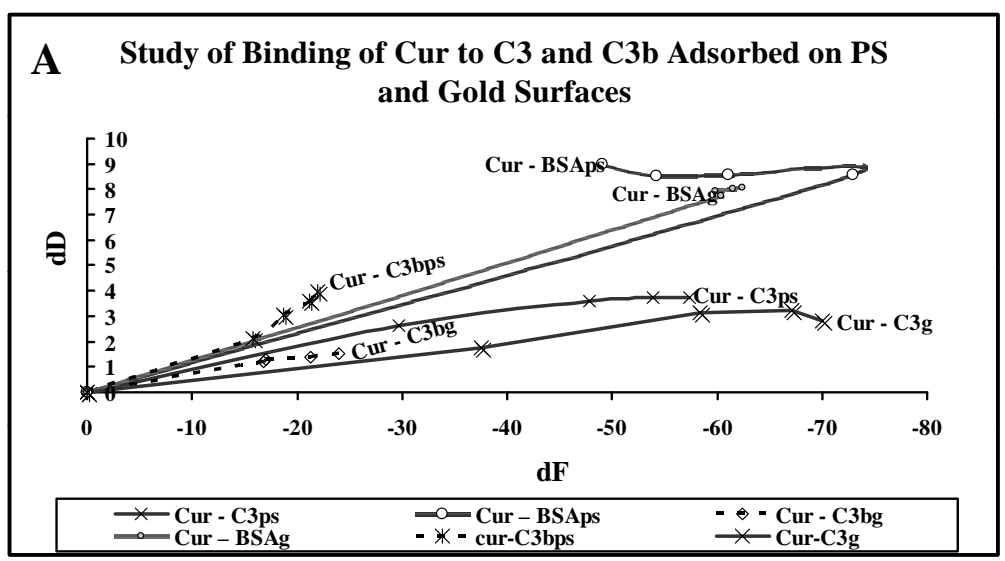

B Study of Binding of Cur to C3 Adsorbed on VCP and tVCP
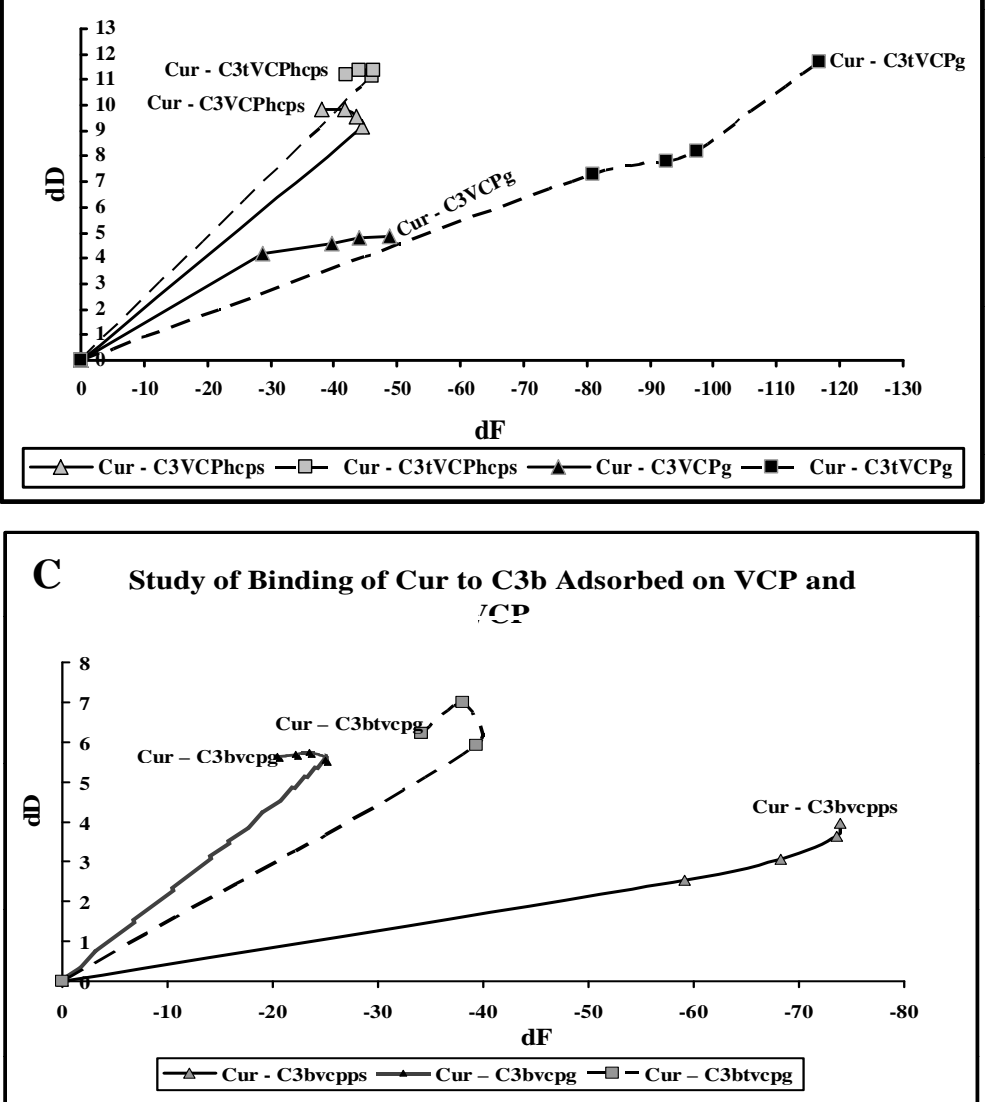

Fig. (10). A. dF values (X-axis) at five different data points for the adsorption of Cur on C3, C3b and BSA adsorbed on gold and PS are plotted against $\mathrm{dD}$ values (Y-axis). The data labels are used to show AMs. The suffix $\mathrm{g}$ or PS in the subscript of an AM indicates that the AM is adsorbed onto either gold or PS surface).

B. $\mathrm{dF}$ values (X-axis) at five different data points for the adsorption of Cur on C3 adsorbed on VCP and tVCP bound to the gold and PS surfaces are plotted against $\mathrm{dD}$ values (Y-axis). The data labels are used to show AMs. The suffix $\mathrm{g}$ or PS in the subscript of an AM indicates that the AM is adsorbed either on gold or PS surface).

C. $\mathrm{dF}$ values (X-axis) at five different data points for the adsorption of Cur C3b adsorbed on VCP and tVCP bound to the gold and PS are plotted against $\mathrm{dD}$ values (Y-axis). The data labels are used to show AMs. The suffix $\mathrm{g}$ or PS in the subscript of an AM indicates that the AM is adsorbed onto either gold or PS surface).

values until the start of the second phase which started at about $-28 \mathrm{~Hz}$. After this, there was a decrease in $\mathrm{dD}$ values. The final $\mathrm{dD}$ values (about 4.87) were higher than that of Cur-C3g (about 2.82; Fig. 10A), but much lower than that of Cur-C3tVCPg (11.67; Fig. 10B). For Cur-C3tVCPps (Fig.
10B), the graph is linear showing only one phase of adsorption with a high $\mathrm{dD}$ value (10.5). For Cur-C3bVCPps (Fig. 10C), the adsorption is almost linear. The final $\mathrm{dD}$ values (3.95) were close to Cur-C3b (3.94) but a drop in $\mathrm{dF}$ 
values (-73.89) was much higher than that of Cur-C3b $(-21.91)$.

\section{DISCUSSION}

QCM studies correlate $\mathrm{dF}$ values with that of the mass of a moiety adsorbed based on the Sauerbrey relation as discussed in the principle of QCM. The adsorption of a protein layer on the crystal surfaces may violate the Sauerbrey relationship [15, 28, 29]. The mass adsorbed cannot be estimated using the $\mathrm{dF}$ values in those cases [15, 30]. However, the frequency shift can reliably be interpreted using another factor called dissipation or D factor [15, 25]. Therefore in QCM-D, in addition to $\mathrm{dF}$ values, the most important factor that can be studied is the factor D which provides information regarding the rigidity of protein binding. $\mathrm{dD} / \mathrm{dF}$ ratios have been used previously to investigate the rigidity of protein binding $[15,26,27]$. These ratios were also defined as $K$ values $(K=\mathrm{dD} / \mathrm{dF})$ by Ayela C. et al. [17]. All these studies show inverse correlation between the ratio and rigidity of the binding, i.e, the lower the ratio for the $\mathrm{P}-\mathrm{P}$ or $\mathrm{P}-\mathrm{S}$ binding, the stronger is the binding. The $\mathrm{dD} / \mathrm{dF}$ ratios for the adsorption of VCP on $\mathrm{C} 3 \mathrm{ps}$ in the current investigation were found to be very low; consequently a very strong binding of $\mathrm{VCP}$ with that of $\mathrm{C} 3 \mathrm{ps}$ is indicated. Using SPR, it is established that VCP inhibits the complement system through its ability to bind to $\mathrm{C} 3 \mathrm{~b}$ [5]. The current findings have added a new dimension to the mode of action of VCP. VCP and tVCP were used at two concentrations in the current study. At lower concentration $(2 \mathrm{~nm})$, the amount of VCP adsorbed on C3 was about 670 $\mathrm{ng} / \mathrm{cm}^{2}$ with $\mathrm{dD}_{\text {fin }} / \mathrm{dF}_{\text {fin }}$ ratio corresponding to about 0.0099 , whereas the amount of $\mathrm{C} 3$ adsorbed on tVCP was about $587.46 \mathrm{ng} / \mathrm{cm}^{2}$ with $\mathrm{dD} / \mathrm{dF}$ ratio of 0.0110 suggesting that VCP binds more strongly to C3 than that of tVCP. When the concentration of VCP was increased by 1.25 times (VCPhc), the amount of VCPhc adsorbed on PS was significantly higher than that of VCP at a low concentration (not shown here). Also, VCPhcps shows adsorption kinetics and the pattern of adsorption different from that of VCPps (not shown), suggesting that both the adsorption kinetics and pattern of adsorption are concentration dependent for VCP. This might be due the ability of VCP to form a dimer as shown by the others [31].

When the binding of VCP and $\mathrm{VVCP}$ to $\mathrm{C} 3$ was compared on the PS surface, $\mathrm{dD} / \mathrm{dF}$ values for $\mathrm{C} 3$-VCPps were less by as much as twice then that for tVCP. However, the amount of $\mathrm{C} 3$ adsorbed on them were found to be the nearly the same (Fig. 4).

The $\mathrm{dD} / \mathrm{dF}$ ratios for the adsorption of Cur on $\mathrm{C} 3$ were greater than that for the adsorption of $\mathrm{C} 3$ on VCP and tVCP, but about 2.8 times smaller than that of Cur-BSAps (Fig. 4). Similar results were observed on the gold surface (Fig. 5). $\mathrm{dD}_{30} / \mathrm{dF}_{30}$ ratio for Cur-C3g binding was three times less than that of Cur-BSAg. Cur showed greater affinity for $\mathrm{C} 3 \mathrm{~g}$ than that of C3ps. However, a greater amount of Cur was adsorbed on $\mathrm{C} 3 \mathrm{~g}$ than that of $\mathrm{C} 3 \mathrm{ps}$. Also, on both the gold and PS surfaces, the amount of Cur adsorbed on C3 was more than that on BSA. Previous studies have shown that BSA binds to Cur [20, 21], and therefore BSA was included as a positive control in the current study. The $\mathrm{dD} / \mathrm{dF}$ ratios were more for Cur-BSA that that of Cur-C3, and the amount of Cur adsorbed onto C3 was also more than that onto BSA. Therefore, from the outcome of the current investigation, it is concluded that Cur shows stronger binding affinity for $\mathrm{C} 3$ than for BSA.

The $\mathrm{dD} / \mathrm{dF}$ ratios for VCPps-C3b and tVCPps-C3b did not differ significantly from each other (Fig. 6). This suggested that both VCPps and tVCPps have an equal affinity for $\mathrm{C} 3 \mathrm{~b}$ at the concentration used in the study. Previous studies using SPR revealed that tVCP does not bind to $\mathrm{C} 3 \mathrm{~b}$ [4]. This could be attributed to the difference in the concentration used, and variation in their methodology. They used amine coupling, as opposed to the adsorption onto PS. The $\mathrm{dD} / \mathrm{dF}$ ratios for $\mathrm{C} 3 \mathrm{~b}-\mathrm{VCPps}$ and $\mathrm{C} 3 \mathrm{~b}-\mathrm{tVCPps}$ were significantly higher than that of C3-VCPps and C3-tVCPps (Fig. 6). This suggested that both VCP and tVCP show greater affinity for $\mathrm{C} 3$ than that for $\mathrm{C} 3 \mathrm{~b}$ on PS. On the gold surface, the amount of $\mathrm{C} 3$ adsorbed onto VCPg is three times more than that for tVCPg (Fig. 5).

The $\mathrm{dD} / \mathrm{dF}$ ratio for $\mathrm{C} 3 \mathrm{~b}-\mathrm{VCPg}$ was found to be approximately 2.8 times less than that of $\mathrm{C} 3 \mathrm{~b}-\mathrm{tVCPg}$, and the amount adsorbed in $\mathrm{ng} / \mathrm{cm}^{2}$ was found to be about three times more for $\mathrm{C} 3 \mathrm{~b}-\mathrm{VCPg}$ than that for $\mathrm{C} 3 \mathrm{~b}-\mathrm{tVCPg}$. These results suggested that $\mathrm{VCP}$ binds to $\mathrm{C} 3 \mathrm{~b}$ to a greater extent than that of tVCP. These results, as opposed to the study on PS, compare with the findings by Smith et al. [4] where they have shown binding of VCP to C3b using SPR. The $\mathrm{dD} / \mathrm{dF}$ ratios for the adsorption of $\mathrm{C} 3 \mathrm{~b}$ onto $\mathrm{VCP}$ and $\mathrm{tVCP}$ bound to the gold and PS surfaces were found to be more than that for $\mathrm{C} 3$ on both the surfaces. This suggests that both VCP and tVCP bind to $\mathrm{C} 3$ more strongly than that of $\mathrm{C} 3 \mathrm{~b}$. VCP binds to $\mathrm{C} 3$ and $\mathrm{C} 3 \mathrm{~b}$ to a greater extent than that of $\mathrm{tVCP}$.

When Cur was tested for its ability to bind to C3bps, $\mathrm{dD} / \mathrm{dF}$ ratios for Cur-C3bps was found to be less than that for Cur-BSAps, which suggested stronger binding of Cur to C3bps. However, dF values as well as the amount of Cur adsorbed onto C3bps was less than that of BSAps (Fig. 6). The results were similar for the adsorption of Cur on $\mathrm{C} 3 \mathrm{bg}$ and BSAg, where the $\mathrm{dD} / \mathrm{dF}$ ratio was found to be less for Cur-C3bg and the amount in $\mathrm{ng} / \mathrm{cm}^{2}$ of Cur adsorbed on C3bg was less than that on BSAg (Fig. 7). The results indicate that Cur binds to $\mathrm{C} 3 \mathrm{~b}$ with more affinity, but the binding is weaker than that of Cur-C3. These findings suggest that inhibition of the $\mathrm{CP}$ and AP shown by Cur using the haemolysis assay and the Quidel kit [5] could therefore be attributed to the ability of Cur to bind to both $\mathrm{C} 3$ and $\mathrm{C} 3 \mathrm{~b}$, but it binds to $\mathrm{C} 3$ with greater affinity than to $\mathrm{C} 3 \mathrm{~b}$.

In previous studies [26, 27], $\mathrm{dD}$ and $\mathrm{dF}$ values at different time points were plotted on a X-Y scatter plot to give information regarding the binding kinetics of AMs. These X-Y scatter plots gave information regarding the phases of adsorption, which in turn provides insight into the nature of adsorption, molecular arrangement or change in conformation during adsorption which might have an impact on the adsorption of the second AM. Therefore, in the current investigation, $\mathrm{dD} v s \mathrm{dF}$ graphs were plotted to get information regarding binding kinetics of the AMs.

The adsorption kinetics for the interaction of VCP and tVCP with that of $\mathrm{C} 3$ and $\mathrm{C} 3 \mathrm{~b}$ adsorbed onto the gold and PS surfaces is shown in Figs. (8 and 9), respectively. As shown in Fig. (9), C3 adsorbs in two phases, with the exception of 
C3-VCPhcps. In all the cases for the adsorption of C3 on VCP and tVCP on both the PS and gold surfaces, the dF values for the last data points are more than $-140 \mathrm{~Hz}$ (except for VCPhcps; Fig. 8), and that for the adsorption of $\mathrm{C} 3 \mathrm{~b}$ on tVCP and VCP, on PS and gold surfaces, being less than -40 $\mathrm{Hz}$, except for C3b-VCPps (Fig. 9). The adsorption kinetics also suggests that $\mathrm{dD}$ values per unit change in $\mathrm{dF}$ values are quite high for the adsorption of $\mathrm{C} 3 \mathrm{~b}$ on both VCP and $\mathrm{VVCP}$ (Fig. 9).

The adsorption kinetics for the adsorption of $\mathrm{C} 3$ and $\mathrm{C} 3 \mathrm{~b}$ on VCP and tVCP suggest that both VCP and tVCP have better affinity for $\mathrm{C} 3$ than that of $\mathrm{C} 3 \mathrm{~b}$ (Figs. 8 and 9). $\mathrm{C} 3 \mathrm{~b}$ shows better adsorption kinetics for VCP than that of tVCP. The lack of module one in tVCP as well as structural difference between $\mathrm{C} 3$ and $\mathrm{C} 3 \mathrm{~b}$ may be attributed to the differences in the adsorption kinetics of these AMs.

The adsorption kinetics for the adsorption of Cur on C3 and $\mathrm{C} 3 \mathrm{~b}$ adsorbed onto PS and gold surfaces, is shown in Fig. (10A). As shown in the results section as well as Fig. (10A), the $\mathrm{dD}$ values per unit change in $\mathrm{dF}$ values are higher for Cur-C3 and Cur-C3b adsorption than that for VCP and tVCP (Figs. 8 and 9).

When Cur was adsorbed onto C3 (Fig. 10B) and C3b (Fig. 10C) bound to VCP or tVCP, there was a sharp increase in $\mathrm{dD}$ values, and the values were on the higher side for Cur-C3tVCPps/g (or Cur-C3btVCPps/g) than that of Cur-C3VCPps/g (or Cur-C3bVCPps/g). For Cur-C3bVCPps the final $\mathrm{dD}$ values were the same as that of Cur-C3bps with a greater decline in $\mathrm{dF}$ values. Similarly, the adsorption kinetics pattern and the final $\mathrm{dD}$ values for $\mathrm{Cur}-\mathrm{C} 3 \mathrm{VCPg}$ were quite close to Cur-C3g. This could be attributed either to an enhanced binding ability of Cur to $\mathrm{C} 3$ and $\mathrm{C} 3 \mathrm{~b}$ bound to VCP, or both VCP and Cur share different binding sites on $\mathrm{C} 3$ and $\mathrm{C} 3 \mathrm{~b}$ which might have resulted in similar $\mathrm{dD}$ values in the respective cases. In the case of adsorption of Cur on $\mathrm{C} 3$ and $\mathrm{C} 3 \mathrm{~b}$ bound to $\mathrm{tVCP}$, there was a sharp rise in $\mathrm{dD}$ values suggesting a very loose binding of Cur. This could be due to sharing of common binding sites by tVCP and Cur.

The mass of AMs adsorbed onto the other AM or onto the gold or PS surface in the QCM-D, could be used to estimate the number of molecules of the binding moieties interacting with each other. In the current investigation, using the Avogadro's formula, the number of molecules interacting with each other is not reported as these estimated values are not accurate as the exact mass of water trapped within the AMs used in the study is unknown. Generally about $30 \%$ of water is trapped within the proteins $[26,32]$. Consequently, this $30 \%$ value was deducted from the final mass of AMs adsorbed onto various surfaces and the other AMs obtained in the current studies. However, water trapped within Cur molecules as well as VCP, and tVCP is not known. Further research is required in this direction. QCM$\mathrm{D}$ could be coupled with the other techniques such as ELM or OWLS to get information regarding the dry mass of the adsorbed compounds, and thereby the information regarding the water bound to protein or protein adlayer could be abtained [16].

In the case of Cur, $\mathrm{dD}$ values were very high in some of the experiments which violate the Sauerbrey law, and therefore the exact amount of these compounds interacting with each other could not be determined.
However, the $\mathrm{dD} / \mathrm{dF}$ ratios and other information reported in this investigation certainly have implications in the development of complement based pharmacotherapeutic agents in the treatment of neuroinflammatory disorders. The binding of VCP and Cur to $\mathrm{C} 3$ and $\mathrm{C} 3 \mathrm{~b}$ found in the current investigation can be correlated with the complement inhibition by them shown previously [1]. VCP was found to be thousand times better than that of Cur in inhibiting the complement mediated haemolysis, and this could be attributed to a better ability of VCP to bind both to C3 and $\mathrm{C} 3 \mathrm{~b}$ than that of Cur as observed in the current investigation. tVCP, which inhibited the CP to a lesser extent could be attributed to the fact that although it adsorbs onto $\mathrm{C} 3$ and $\mathrm{C} 3 \mathrm{~b}$, the binding is variable, and it does not bind to $\mathrm{C} 3$ and $\mathrm{C} 3 \mathrm{~b}$ as strongly as VCP.

As discussed in the introduction, a polystyrene surface activates $\mathrm{C} 3$. VCP, tVCP as well as Cur were able to inhibit the same. These compounds inhibited $\mathrm{C} 3$ to a greater extent than that of $\mathrm{C} 3 \mathrm{~b}$.

In conclusion, in the current study, QCM-D was successfully employed to obtain information regarding the interaction of VCP, tVCP, and Cur with $\mathrm{C} 3$ and $\mathrm{C} 3 \mathrm{~b}$. VCP showed greater binding affinity for both the $\mathrm{C} 3$ and $\mathrm{C} 3 \mathrm{~b}$ than Cur and tVCP. The binding of VCP and tVCP to $\mathrm{C} 3$ and $\mathrm{C} 3 \mathrm{~b}$ was orientation dependent. In addition, it was shown that Cur binds to both $\mathrm{C} 3$ and $\mathrm{C} 3 \mathrm{~b}$. However, all these compounds show greater affinity for $\mathrm{C} 3$ than $\mathrm{C} 3 \mathrm{~b}$. VCP is a thousand fold stronger inhibitor of complement than Cur, and is known to inhibit amyloid mediated complement activation [33]. Cur is a weak inhibitor of complement, but dissolves plaques [34]. The current investigation suggests that both VCP and Cur probably share different binding sites on $\mathrm{C} 3$ and $\mathrm{C} 3 \mathrm{~b}$, and thus may not interfere with each others actions on the complement system. Due to their broad spectrum anti-inflammatory activities covering different aspects of inflammation, and possibility of sharing different binding sites by them as discussed above, further research is recommended in the direction of developing a combination therapy or "synergistic cocktail" by mixing Cur and VCP to prevent the complement mediated neurodegeneration in amyloidopathies. Just like curcumin, many other small sized complement regulatory molecules could be exploited to study the mode of complement inhibition by them using QCM-D technology. Polyhydroxy phenolic compounds, terpenes, esters, and the compounds of natural origin belonging to different chemical classes thoroughly reviewed in a recent article [1] could also be investigated for the complement regulatory activity by them. These compounds may inhibit various stages of activation of the complement system and could be used to develop combinatorial therapy to treat disorders of the brain where the complement system is activated. The same technology could also be used study the interaction of these molecules with other receptor molecules as well. The current investigation has shown that QCM-D could be applied to develop a better understanding of complement regulatory agents with therapeutic effectiveness.

\section{ACKNOWLEDGEMENTS}

We thank Dr. Abdul Ajees from the University of Alabama in the USA for providing us the complement 
components C3 and C3b. GJK was a Senior Wellcome Trust International Fellow for biomedical Sciences in South Africa during the intiation, design and planning of this work. The Q-sense D-300 was purchased from the funds provided to GJK by University of Cape Town Equipment Committee. APK was supported by PRF, UCT-research associateship, SEM and International student's fellowship at UCT. APK is currently supported by the Claude Leon Foundation, UK. Authors are also grateful to Mr. Stuart Mailer for his help with providing the PEG-COOH crystals for the study prior to collecting the data for this article.

\section{REFERENCES}

[1] Kulkarni, A.; Ghebremariam, Y.; Kotwal, G. Curcumin inhibits the classical and the alternate pathways of complement activation. Ann N. Y. Acad. Sci., 2005, 1056, 100-112.

[2] Kotwal, G.; Moss, B. Vaccinia virus encodes a secretory polypeptide structurally related to complement control proteins. Nature, 1988, 335, 176-178.

[3] Kotwal, G.; Isaacs, S.; McKenzie, R.; Frank, M.; Moss, B. Inhibition of the complement cascade by the major secretary protein of vaccinia virus. Science, 1990, 250, 827-830.

[4] McKenzie, R.; Kotwal, G.; Moss, B.; Hammer, C.; Frank, M. Regulation of complement activity by vaccinia virus complementcontrol protein. J. Infect. Dis., 1992, 166, 1245-1250.

[5] Smith, S.; Sreenivasan, R.; Krishnasamy, G.; Judge, K.; Murthy, K.; Arjunwadkar, S.; Pugh, D.; Kotwal, G. Mapping of regions within the vaccinia virus complement control protein involved in dose-dependent binding to key complement components and heparin using surface plasmon resonance. Biochim. Biophys. Acta, 2003, 1650, 30-39.

[6] Hinshelwood, J.; Spencer, D.; Edwards, Y.; Perkins, S. Identification of the C3b binding site in a recombinant vWF-A domain of complement factor B by surface-enhanced laser desorption ionisation affinity mass spectrometry and homology modelling: implications for the activity of factor B. J. Mol. Biol., 1999, 294, 587-599.

[7] Makrides, S.C. Therapeutic inhibition of the complement system. Pharmacol. Rev., 1998, 50, 59-87.

[8] Datta, P.K..; Rappaport, J. HIV and complement: hijacking an immune defense. Biomed. Pharmacother., 2006, 60, 561-568.

[9] Speth, C.; Schabetsberger, T.; Mohsenipour, I.; Stöckl, G.; Würzner, R.; Stoiber, H.; Lass-Flörl, C.; Dierich, M. Mechanism of human immunodeficiency virus-induced complement expression in astrocytes and neurons. J. Virol., 2002, 76, 3179-3188. Available from: http://www.ncbi.nlm.nih.gov/pmc/articles/PMC136041/pdf/ 1959.pdf

[10] Stoiber, H.; Pruenster, M.; Christoph, G.; Ammanna, C.; Dierich, M. Complement-opsonized HIV: the free rider on its way to infection. Mol. Immunol., 2005, 42, 153-160.

[11] Spear, G.; Olinger, G.; Sullivan, B.; Landay, A.; Kessler, H.; Connick, E.; Kuritzkes, D.; St Clair, M.; Spritzler, J.; Wu, H.; Lederman, M. Alteration of complement protein levels after antiretroviral therapy in HIV-infected persons. AIDS Res. Hum. Retroviruses, 1999, 15, 1713-1715.

[12] Zhou, J.; Fonseca, M.; Pisalyaput, K.; Tenner, A. Complement C3 and $\mathrm{C} 4$ expression in C1q sufficient and deficient mouse models of Alzheimer's disease. J. Neurochem., 2008, 106, 2080-2092.

[13] Zanjani, H.; Finch, C.; Kemper, C.; Atkinson, J.; McKeel, D.; Morris, J.; Price, J. Complement activation in very early Alzheimer disease. Alzheimer Dis. Assoc. Disord., 2005, 19, 55-66.

[14] Ramsden, J. Experimental methods for investigating protein adsorption kinetics at surface. Q. Rev. Biophys., 1993, 27, 41-105.

[15] Höök, F. Thesis, Chalmers University of Technology, Goetberg University, Goetborg, Sweden 2004.

[16] Höök, F.; Vörös, J.; Rodahl, M.; Kurrat, R.; Böni, P.; Ramsden, J.; Textor, M.; Spencer, N.; Tengvall, P.; Gold, J.; Kasemo, B. A comparative study of protein adsorption on titanium oxide surfaces using in situ ellipsometry, optical waveguide lightmode spectroscopy, and quartz crystal microbalance/dissipation. Colloids Surf. B. Biointerface, 2002, 24, 155-170.

[17] Ayela, C.; Roquet, F.; Valera, L.; Granier, C.; Nicu, L.; Pugni`ere, M. Antibody-antigenic peptide interactions monitored by SPR and QCM-D. A model for SPR detection of IA-2 autoantibodies in human serum. Biosens. Bioelectron., 2007, 22, 3113-3119.

[18] Vikinge, T.; Hansson,K.; Liedberg, P.; Lindahl, T.; Lundstro"m, I.; Tengvall, P.; Höök, F. Comparison of surface plasmon resonance and quartz crystal microbalance in the study of whole blood and plasma coagulation. Biosens. Bioelectron., 2000, 15, 605-613.

[19] Aberl, F.; Wolf, H.; Kößlinger, C.; Drost, S.; Woias, P.; Koch, S. HIV serology using piezoelectric immunosensors. Sens. Actuators B. Chem., 1994, 18-19, 271-275.

[20] Guicai, L; Xiaoli, S.; Ping, Y. Ansha, Z. Nan, H. Investigation of fibrinogen adsorption on solid surface by quartz crystal microbalance with dissipation (QCM-D) and ELISA. J. Solid State Ionics, 2008, 179, 932-935.

[21] Andersson, J.; Ekdahl, K.; Lambris, J.; Nilsson, B. Binding of C3 fragments on top of adsorbed plasma proteins during complement activation on a model biomaterial surface. Biomaterials, 2005, 26 , $1477-1485$.

[22] Andersson, J.; Larsson, R.; Richter, R.; Ekdahl, K.; Nilsson, B. Binding of a model regulator of complement activation (RCA) to a biomaterial surface: surface-bound factor $\mathrm{H}$ inhibits complement activation. Biomaterials, 2001, 22, 2435-2443.

[23] Barik, A.; Priyadarsini, K.; Mohan, H. Photophysical studies on binding of curcumin to bovine serum albumins. Photochem. Photobiol., 2003, 77, 597-603.

[24] Sahoo, B.K.; Ghosh, K.S.; Dasgupta, S. Investigating the binding of curcumin derivatives to bovine serum albumin. Biophys. Chem., 2008, 132, 81-88.

[25] Rodahl, M.; Höök, F.; Fredriksson, C.; Keller, C.; Krozer, A.; Brzezinski, P.; Voinova, M.; Kasemo, B. Simultaneous frequency and dissipation factor QCM measurements of biomolecular adsorption and cell adhesion. Faraday Discuss., 1997, 107, 229246.

[26] Höök, F.; Rodahl, M.; Brzezinski, P.; Kasemo, B. Energy dissipation kinetics for protein and antibody-antigen adsorption under shear oscillation on a quartz crystal microbalance. Langmuir, 1998, 14, 729-734

[27] Höök, F.; Rodahl, M.; Kasemo, B.; Brzezinski, P. Structural changes in hemoglobin during adsorption to solid surfaces: effects of $\mathrm{pH}$, ionic strength, and ligand binding. Proc. Natl. Acad. Sci. USA, 1998, 95, 12271-122276.

[28] Thompson, M.; Arthur, C.; Dhaliwal, G. Liquid-phase piezoelectric and acoustic transmission studies of interfacial immunochemistry. Anal. Chem., 1986, 58, 1206-1209.

[29] Ward, M.; Buttry, D. In situ interfacial mass detection with piezoelectric transducers. Science, 1990, 249, 1000-1007.

[30] Caruso, F.; Furlong, D.; Kingshott. P. Characterization of ferritin adsorption onto gold. J. Colloid Interface Sci., 1997, 186, 129-140.

[31] Liszewski, M.; Leung, M.; Hauhart, R.; Mark, R.; Buller, L.; Bertram, P.; Wang, X.; Rosengard, A.; Kotwal, G.; Atkinson, J. Structure and regulatory profile of the monkeypox inhibitor of complement: comparison to homologs in vaccinia and variola and evidence for dimer formation. J. Immunol., 2006, 176, 3725-3734.

[32] Saenger, W. Structure and dynamics of water surrounding biomolecules. Аnпи. Rev. Biophys. Biophys. Chem., 1987, 16, 93114.

[33] Daly, J.; Kotwal, G. Pro-inflammatory complement activation by the $A \beta$ peptide of alzheimer's disease is biologically significant and can be blocked by vaccinia virus complement control protein. Neurobiol. Aging, 1998, 19, 619-627.

[34] Yang, F.; Lim, G.; Begum, A.; Ubeda, O.; Simmons, M.; Ambegaokar, S.; Chen, P.; Kayed, R.; Glabe, C.; Frautschy, S.; Cole, G. Curcumin inhibits formation of amyloid \{beta\} oligomers and fibrils, binds plaques, and reduces amyloid in vivo. J. Biol. Chem., 2005, 280, 5892-5901. 